Article

\title{
Isothermal Crystallization Kinetics of Poly(ethylene terephthalate) Copolymerized with Various Amounts of Isosorbide
}

\author{
Nicolas Descamps ${ }^{1}$, Florian Fernandez ${ }^{1,2}$, Pierre Heijboer ${ }^{3}$, René Saint-Loup ${ }^{4}$ and \\ Nicolas Jacquel ${ }^{4, *}$ \\ 1 Functional Properties Analysis Department, Roquette Frères, Rue de la Haute Loge, 62080 Lestrem, France \\ École nationale supérieure de chimie de Lille, Avenue Mendeleiev, 59652 Villeneuve-d'Ascq, France \\ Analytical Research Department, Roquette Frères, Rue de la Haute Loge, 62080 Lestrem, France \\ 4 Performance Materials and Cosmetic, Roquette Frères, Rue de la Haute Loge, 62080 Lestrem, France \\ * Correspondence: nicolas.jacquel@roquette.com
}

Received: 19 December 2019; Accepted: 25 January 2020; Published: 5 February 2020

\begin{abstract}
Poly(ethylene-co-isosorbide terephthalate) (PEIT) copolyesters could be used in various applications depending on their ability to crystallize. Moreover, the possibility to carry out solid-state post-condensation (SSP) is conditioned by its ability to sufficiently crystallize. The present study, thus, gives a systematic investigation of isothermal crystallization of these statistical copolyesters with isosorbide contents ranging from 4.8 to $20.8 \mathrm{~mol}$ \%. For each copolyester composition, the lowest isothermal half crystallization times and the highest Avrami constant $(\mathrm{K})$ were obtained around $170{ }^{\circ} \mathrm{C}$. Over the range of composition that was studied, both melting points and melting enthalpies decreased with increasing amounts of isosorbide (from 250 to $207^{\circ} \mathrm{C}$ and from 55 to $28 \mathrm{~J} / \mathrm{g}$, respectively). On the contrary, half crystallization time displayed an exponential increase when increasing isosorbide contents in the studied range. Finally, structural and thermal analysis of PIT homopolyester are reported for the first time, showing that only ET moieties crystallized when PEIT was subjected to isothermal crystallization at $170^{\circ} \mathrm{C}$.
\end{abstract}

Keywords: crystallization; kinetics; poly(ethylene-co-isosorbide terephthalate); isosorbide; copolyester

\section{Introduction}

In recent years, several bio-based monomers were studied for the improvement of polycondensate properties or for the replacement of petrochemical monomers. The 1,4:3,6-dianhydrohexitols (DAHs), namely isomannide, isosorbide, and isoidide are produced in two steps: hydrogenation of glucose and dehydration of the corresponding hexitol. Of the three known isohexide isomers, only dianhydro-1,4:3,6-D-sorbitol (DAS) or isosorbide is currently produced with sufficient purity for polymerization on an industrial scale. Due to their rigidity and their harmlessness, these molecules are gaining more interest for their use as building blocks in various polymers in the field of thermoplastic materials and for curable resin applications [1,2]. As a diol, isosorbide found its place as a monomer suitable for polycondensate synthesis like polyesters, polycarbonates, and thermoplastic polyurethanes [3]. In polycarbonate, isosorbide not only allows the substitution of toxic bisphenol A (BPA), but offers a significant increase in the mechanical strength, heat resistance, UV resistance, and optical properties, with resulting properties between common BPA polycarbonate and PMMA.

In polyesters, isosorbide was copolymerized in polymers such as poly(ethylene terephthalate) (PET) [4-6], poly(trimethylene terephthalate) (PTT) [7], poly(butylene terephthalate) (PBT) [8,9], and poly(cyclohexanedimethylene terephthalate) (PCT) [10] for its ability to increase the heat resistance 
of the polymer. As an example, in the case of PET, isosorbide allows for an outstanding increase in $\mathrm{Tg}$. In the 1990s, Storbeck et al. [11] demonstrated that the Tg followed a linear increase with a slope of $1.2{ }^{\circ} \mathrm{C}$ per $1 \mathrm{~mol} . \%$ of isosorbide incorporated in the substitution of ethylene glycol.

Depending on the amount of isosorbide introduced in the polymer, different final applications can be targeted. As an example for the lower amounts of isosorbide, the semi-crystalline properties of the polymer can be preserved, allowing its modification via solid-state post-condensation (SSP), followed by its use in injection stretch blow molding (ISBM) of a bottle or the melt spinning of fibers. In the final shaped objects, the gain in thermal stability due to the addition of isosorbide extends their range of applicability (i.e., hot filling of bottles or making heat-resistant fibers). When isosorbide is used in higher proportions ( $>20 \mathrm{~mol} . \%$ ), it induces larger variations in the crystallization behavior of PET, thus resulting in amorphous copolymers with a $\mathrm{Tg}$ above $100^{\circ} \mathrm{C}$. These fully amorphous polymers can then compete with transparent high-Tg polymers such as polycarbonates (PC) or poly(methyl methacrylate) (PMMA).

The aim of this paper is to provide a deeper study of the crystallization kinetics of various PEITs with isosorbide molar contents $(0 \%$ to $20 \%)$ in a large temperature range from $130{ }^{\circ} \mathrm{C}$ to $190{ }^{\circ} \mathrm{C}$. These data are particularly of interest in order to precisely identify in which range of isosorbide content could poly(ethylene-co-isosorbide terephthalate) be used in semi-crystalline applications.

\section{Experimental Section}

\subsection{Materials}

Terephthalic acid $(99 \%+)$ was purchased from Acros organics (Geel, Belgium), ethylene glycol (99.8\%) was purchased from Aldrich (Saint-Louis, MO, USA), and high-purity Polysorb®isosorbide $(>99.5 \%)$ was obtained from Roquette (Lestrem, France) was used. Each of these chemicals was used as received without further purification.

\subsection{General Procedure for PEIT (and PET) Synthesis}

Polymer samples were synthesized via a two-step, melt polycondensation reaction (esterification and transesterification, see Figure 1) in a 7.5-L stainless-steel batch reactor equipped with a heating system, a mechanical stirrer with torque measurement, a distillation column, a vacuum line, and a nitrogen-gas inlet.

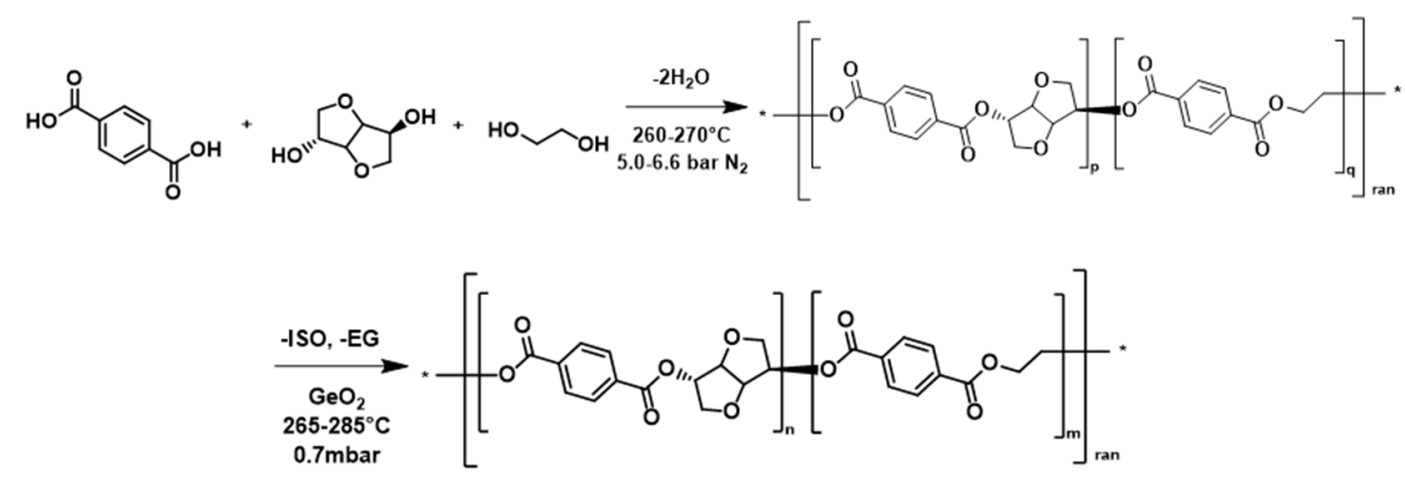

Figure 1. General scheme of poly(ethylene-co-isosorbide terephthalate (PEIT) synthesis from terephthalic acid, isosorbide, and ethylene glycol.

In the first step, the reactor was charged with $2656 \mathrm{~g}$ (16 moles) of terephthalic acid and 19.2 moles of diol (comprising isosorbide and ethylene glycol). Other additives such as anti-diethylene glycol, antioxidants, and catalysts were also fed into the paste. To exclude residual oxygen from the isosorbide crystals as much as possible, four vacuum-nitrogen cycles were carried out between 60 and $80^{\circ} \mathrm{C}$. The reaction mixture was then heated up to $260^{\circ} \mathrm{C}$ under a nitrogen pressure of 5.0 bar $\left(270{ }^{\circ} \mathrm{C}\right.$ and 
6.6 bar for PET) and stirred at a constant rate (150 rpm). The esterification rate was estimated from the quantity of distillate collected. In the second step, the pressure was reduced in $90 \mathrm{~min}$ to $0.7 \mathrm{mbar}$, and the temperature was gradually increased to $270{ }^{\circ} \mathrm{C}\left(285^{\circ} \mathrm{C}\right.$ for PET). Low-pressure conditions were maintained for $90 \mathrm{~min}$, and the viscosity variation of the polymer was measured from the torque applied on the stirrer. A polymer strand was then withdrawn from the bottom drain valve of the reactor and quenched in a water bath. PEIT pellets $(15 \mathrm{mg})$ were obtained after granulation. Using such a procedure avoids contact of the warm polymer with oxygen, thus reducing coloration and thermo-oxidative degradation.

For comparison purposes, PIT was synthetized using the same procedure.

\section{Polymer Characterization}

\subsection{Reduced Viscosity}

The reduced viscosity $\left(\eta_{\text {red }}\right)$ of the polymers was determined using an automated Ubbelohde capillary at $35^{\circ} \mathrm{C}$. The polymer samples were dissolved in ortho-chlorophenol (Aldrich, Saint-Louis, $\mathrm{MO}, \mathrm{USA}$ ) at a concentration of $\mathrm{C}=5 \mathrm{~g} / \mathrm{L}$ at $135^{\circ} \mathrm{C}$. Then, the reduced viscosities were calculated using Equation (1), where $t_{0}$ and $t_{s}$ refer to the neat solvent and the polymer/solvent solution flow times, respectively.

$$
\eta_{\text {red }}=\frac{\left(t_{s}-t_{0}\right)}{t_{0} \cdot C}
$$

\section{2. ${ }^{1} \mathrm{H}-\mathrm{NMR}$ Analysis}

The ${ }^{1} \mathrm{H}-\mathrm{NMR}$ analysis of PEIT was carried out using a 400-MHz Bruker liquid-state NMR spectrometer (Billerica, MA, USA) equipped with a QNP probe. The polymer was dissolved in deuterated chloroform and trifluoroacetic acid (3:1 v/v) before analysis. All NMR measurements were recorded at $25^{\circ} \mathrm{C}$. The calculations of the isosorbide content were done according to method described by Bersot et al. [4].

\section{3. ${ }^{13} \mathrm{C}-\mathrm{NMR}$ Analysis}

The distribution of the repetitive units in PEIT was assessed by ${ }^{13} \mathrm{C}$-NMR spectrometry at $25^{\circ} \mathrm{C}$ in a solution of $\mathrm{CDCl}_{3}+$ TFA-d1 ( $\sim 95 \mathrm{mg}$ of polymer sample in $0.6 \mathrm{~mL}$ of $\mathrm{CDCl}_{3}+0.1 \mathrm{~mL}$ TFA-d1).

\subsection{Differential Scanning Calorimetry (DSC)}

The differential scanning calorimetry (DSC, experiments were performed using a TA instruments Q20 calorimeter (New Castle, DE, USA). The instrument was calibrated for temperature and enthalpy using the melting temperature and the heat of fusion of indium $\left(156.6^{\circ} \mathrm{C}\right.$ and $\left.28.57 \mathrm{~J} / \mathrm{g}\right)$. The analyses were carried out on typically $10 \mathrm{mg}$ of material in aluminum pans of $40 \mu \mathrm{L}$. Polyesters may take up a little moisture during storage. Therefore, pans were not sealed to ensure that water adsorbed could evaporate to investigate the behavior of dry samples. The DSC oven was flushed with dry nitrogen gas $(40 \mathrm{~mL} / \mathrm{min})$. In order to analyze and compare the influence of various thermal treatments on the samples, all calorimetric measurements were performed at a standard heating rate of $10^{\circ} \mathrm{C} / \mathrm{min}$. The reference $\mathrm{Tg}$ of each sample was defined as the midpoint of the glass transition heat flow jump. The melting temperature was defined as the peak temperature of the melting endotherm.

The crystallization kinetics of PEIT was measured from the melt to erase any thermal history of the sample. For that, a first heating ramp from room temperature to $20{ }^{\circ} \mathrm{C}$ above the end of the melting endotherm was done. This first scan was followed by an isotherm of five minutes at the temperature reached to ensure that all crystallites were melted and that remaining water was evaporated. The sample was then quickly equilibrated at the crystallization temperature to undergo the crystallization isotherm. According to the isosorbide content, two procedures were followed. 
For isosorbide content lower than or equal to $15 \%$, crystallization kinetics was quick enough so that the crystallization exotherm $\left(\mathrm{H}_{\text {cryst }}\right)$ could be measured directly on the isothermal signal of the DSC. The relative crystallization rate $\mathrm{X}$ can be expressed as follows:

$$
X(t)=\frac{\int_{t_{0}}^{t}\left(d H_{\text {cryst }} / d t\right) d t}{\int_{t_{0}}^{t_{f}}\left(d H_{\text {cryst }} / d t\right) d t},
$$

where $t$ is the time and $t_{f}$ is the time for a complete crystallization.

For isosorbide contents higher than $15 \%$, crystallization kinetics was too long to get a precise enough isothermal signal. Therefore, after the crystallization isotherm, samples were cooled down below their Tg and heated up again at $10{ }^{\circ} \mathrm{C} / \mathrm{min}$ up to their melting temperature. During this last step, the melting enthalpy $\left(\Delta \mathrm{H}_{\text {melting }}\right)$ could be recorded. The relative crystallization rate $\mathrm{X}$ was calculated as follows:

$$
X(t)=\frac{\Delta \mathrm{H}_{\text {melting }}(\mathrm{t})}{\Delta \mathrm{H}_{\text {melting } \max }}
$$

where $\Delta \mathrm{H}_{\text {melting max }}$ is the maximum melting enthalpy recorded on the considered sample. In Equations (2) and (3), $X(t)$ expresses the relative crystallinity of the sample.

\subsection{Powder X-ray diffraction (PXRD)}

Powder X-ray diffraction experiments were performed on 2-mm-thick polyester sheets with a Brucker D8 Advance diffractometer (Billerica, MA, USA) using a copper anticathode. Prior to measurements, samples were placed at $170^{\circ} \mathrm{C}$ for the appropriate time to get a complete crystallization.

\section{Results}

Poly(ethylene-co-isosorbide terephthalate) samples with varying isosorbide contents were produced at the pilot scale by Roquette Frères. The isosorbide content is expressed as the molar percentage of ethylene glycol replaced by isosorbide. The characteristics of the studied samples are presented in Table 1.

Table 1. Characteristics of studied samples. PEIxT corresponds here to a PEIT containing x\% molar

\begin{tabular}{|c|c|c|c|c|c|c|c|c|c|c|c|}
\hline \multirow[t]{2}{*}{$\begin{array}{l}\text { Samples } \\
\text { Code }\end{array}$} & \multirow[t]{2}{*}{$\begin{array}{l}\text { Isosorbide } \\
\text { in Polymer }\end{array}$} & \multirow{2}{*}{$\begin{array}{c}\text { Reduced } \\
\text { Viscosity } \\
(d L / g)\end{array}$} & \multicolumn{3}{|c|}{ Triad Molar Fraction } & \multicolumn{2}{|c|}{$\begin{array}{c}\text { Average Sequence } \\
\text { Lengths }\end{array}$} & \multirow{2}{*}{$\begin{array}{c}\text { Degree of } \\
\text { Randomness } \\
\text { (R) }\end{array}$} & \multicolumn{3}{|c|}{ Coloration } \\
\hline & & & ITI & ITE + ETI & ETE & n ET & n IT & & $\mathbf{L}^{*}$ & $a^{*}$ & $\mathbf{b}^{*}$ \\
\hline PET & 0 & 0.71 & - & - & - & - & - & - & - & - & - \\
\hline $\mathrm{PEI}_{4.9} \mathrm{~T}$ & 4.9 & 0.65 & 0 & 9.4 & 90.6 & 20.3 & 1.0 & 1.05 & 51.8 & 0.2 & -1.9 \\
\hline $\mathrm{PEI}_{6.5} \mathrm{~T}$ & 6.5 & 0.59 & - & - & - & - & - & - & 55.8 & 0.1 & 0.6 \\
\hline $\mathrm{PEI}_{9.8} \mathrm{~T}$ & 9.8 & 0.66 & 3.2 & 17.7 & 79.1 & 9.9 & 1.4 & 0.84 & 52.1 & -0.1 & 1.4 \\
\hline $\mathrm{PEI}_{10.9} \mathrm{~T}$ & 10.9 & 0.59 & - & - & - & - & - & - & 57.5 & -0.2 & 1.3 \\
\hline $\mathrm{PEI}_{17.1} \mathrm{~T}$ & 17.1 & 0.61 & 4.2 & 26.7 & 69.0 & 6.2 & 1.3 & 0.92 & 52.8 & -0.2 & -0.6 \\
\hline $\mathrm{PEI}_{19.5} \mathrm{~T}$ & 19.5 & 0.60 & - & - & - & - & - & - & 56.1 & -0.6 & 2.7 \\
\hline $\mathrm{PEI}_{20.8} \mathrm{~T}$ & 20.8 & 0.56 & 6.3 & 30.2 & 63.6 & 5.2 & 1.4 & 0.90 & 50.0 & -0.6 & 1.4 \\
\hline PIT & 100 & 0.21 & - & - & - & - & - & - & - & - & - \\
\hline
\end{tabular}
of isosorbide.

The results show that PEIT samples with isosorbide content from 4.9 to $20.8 \mathrm{~mol} . \%$ were successfully synthetized. Moreover, based on the equation with the polymerization conditions used, the final polymer displayed no coloration. Color parameters were evaluated, and $L^{*}$ was higher than 50 , a* was between -0.6 and 0.2 , and $b^{*}$ was between -1.9 and 2.7 . These polymers also displayed reduced viscosities ranging from 0.56 to $0.66 \mathrm{dL} / \mathrm{g}$, indicating that high-molar-mass polyesters were achieved. In this small range of reduced viscosity, it was considered that the molar mass of the polymer had a limited effect on the crystallization kinetics of the polymer. For comparison purposes, a polyester 
made from isosorbide and terephthalic acid only was synthetized. The product displayed a reduced viscosity of $0.21 \mathrm{dL} / \mathrm{g}$ and a $\mathrm{Tg}$ of $140{ }^{\circ} \mathrm{C}$.

In order to see the possible influence of the structure of the polymer on crystallization, copolyester triads were further assessed by ${ }^{13} \mathrm{C}-\mathrm{NMR}$ analysis. Identification and quantification of triads were done by analysis of quaternary carbons of terephthalic acid moieties located in the 132-134 ppm region. Depending on the neighboring diols, these carbons presented variable chemical shifts, as shown in Figure 2.

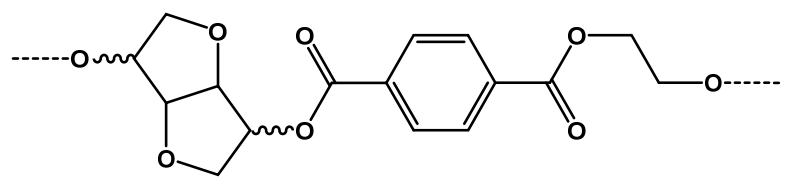

ITE or ETI

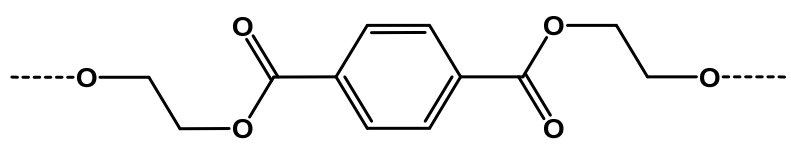

ETE

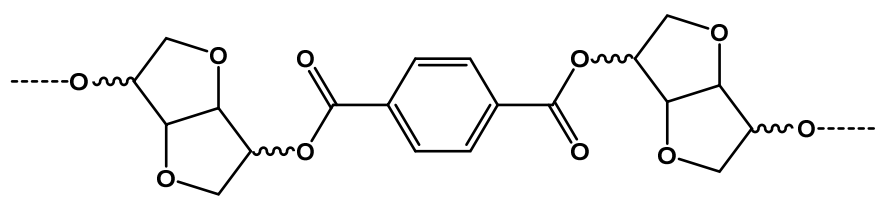

ITI

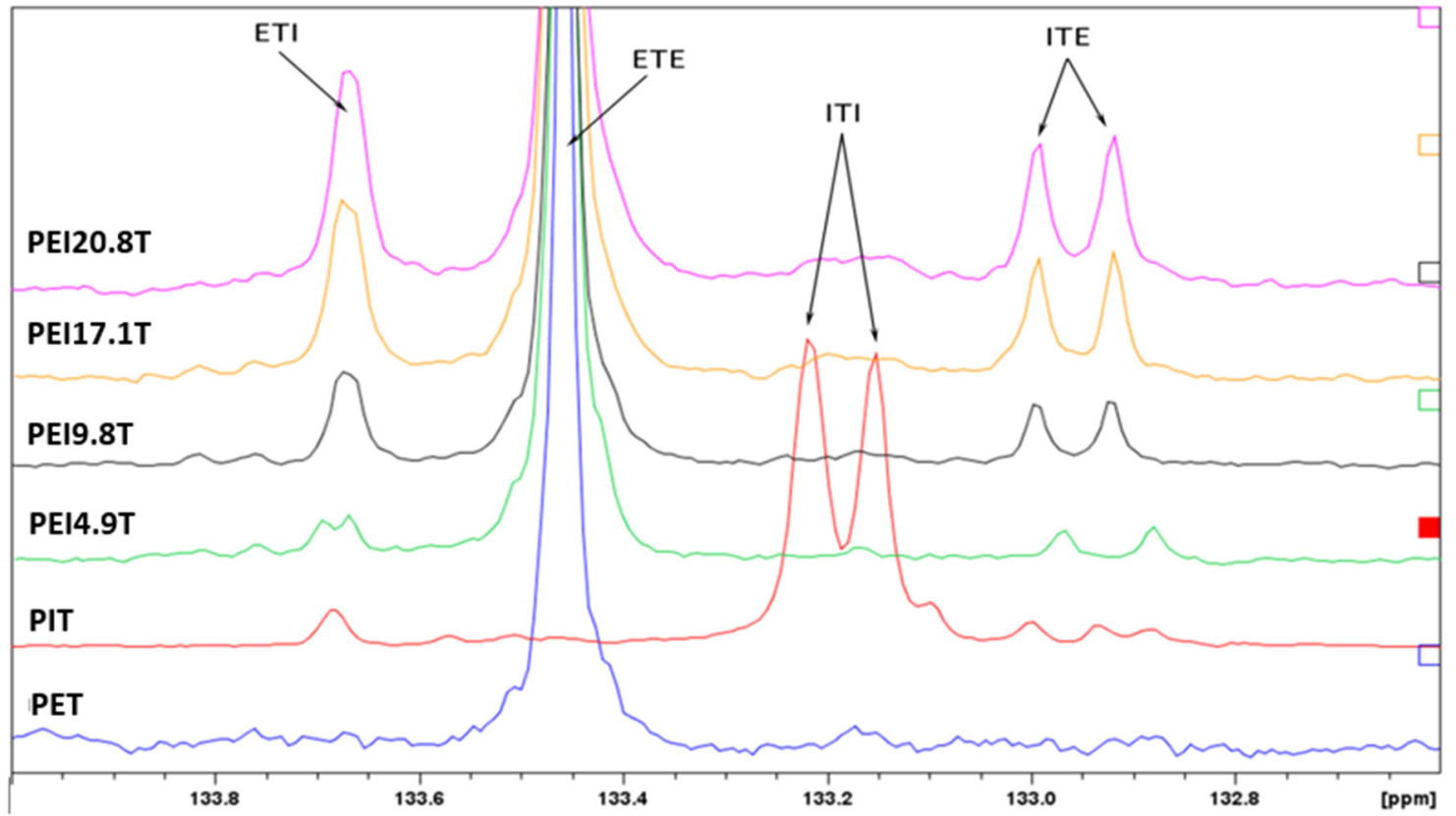

Figure $2 .{ }^{13} \mathrm{C}-\mathrm{NMR}$ chemical shifts of the different sequences in PEIT.

Thus, from the integration of these signals, it was possible to evaluate the average sequence length of both ethylene terephthalate (ET) and isosorbide terephthalate (IT) moieties with the following equations [12]:

$$
\begin{gathered}
\mathrm{n}_{\mathrm{ET}}=\frac{\mathrm{I}_{\mathrm{ETE}}+\frac{\mathrm{I}_{\mathrm{ITE}+\mathrm{ETI}}}{2}}{\frac{\mathrm{I}_{\mathrm{ITE}}+\mathrm{ETI}}{2}}, \\
\mathrm{n}_{\mathrm{IT}}=\frac{\mathrm{I}_{\mathrm{ITI}}+\frac{\mathrm{I}_{\mathrm{ITE}+\mathrm{ETI}}}{2}}{\frac{\mathrm{I}_{\mathrm{ITE}+\mathrm{ETI}}}{2}} .
\end{gathered}
$$


Thus, the degree of randomness $\mathrm{R}$ could be evaluated as follows:

$$
\mathrm{R}=\frac{1}{\mathrm{n}_{\mathrm{ET}}}+\frac{1}{\mathrm{n}_{\mathrm{IT}}}
$$

$R$ takes 2 as a value for an alternating copolymer, 1 for a random structure, $<1$ for a sequential block structure, and 0 for a mixture of homopolymers [13].

Results from this sequence analysis show that the ET sequence length decreased from 22.3 to 5.2, while the isosorbide content increased from 4.2 to $20.8 \mathrm{~mol} \%$.

\section{Isothermal crystallization kinetics}

As detailed previously, the isothermal crystallization of PEIT with varying isosorbide contents was studied by DSC with two different protocols. For low isosorbide contents $(\leq 15 \%$ molar of ethylene glycol replaced by isosorbide), the crystallization kinetics could be directly observed on the isothermal thermogram (see Figure 3). For isosorbide content higher than 15\%, the crystallization process was too long to be precisely observed in the same way. Therefore, the crystallization kinetics was followed by measuring the melting enthalpy of the crystallized material (see Figure 4).

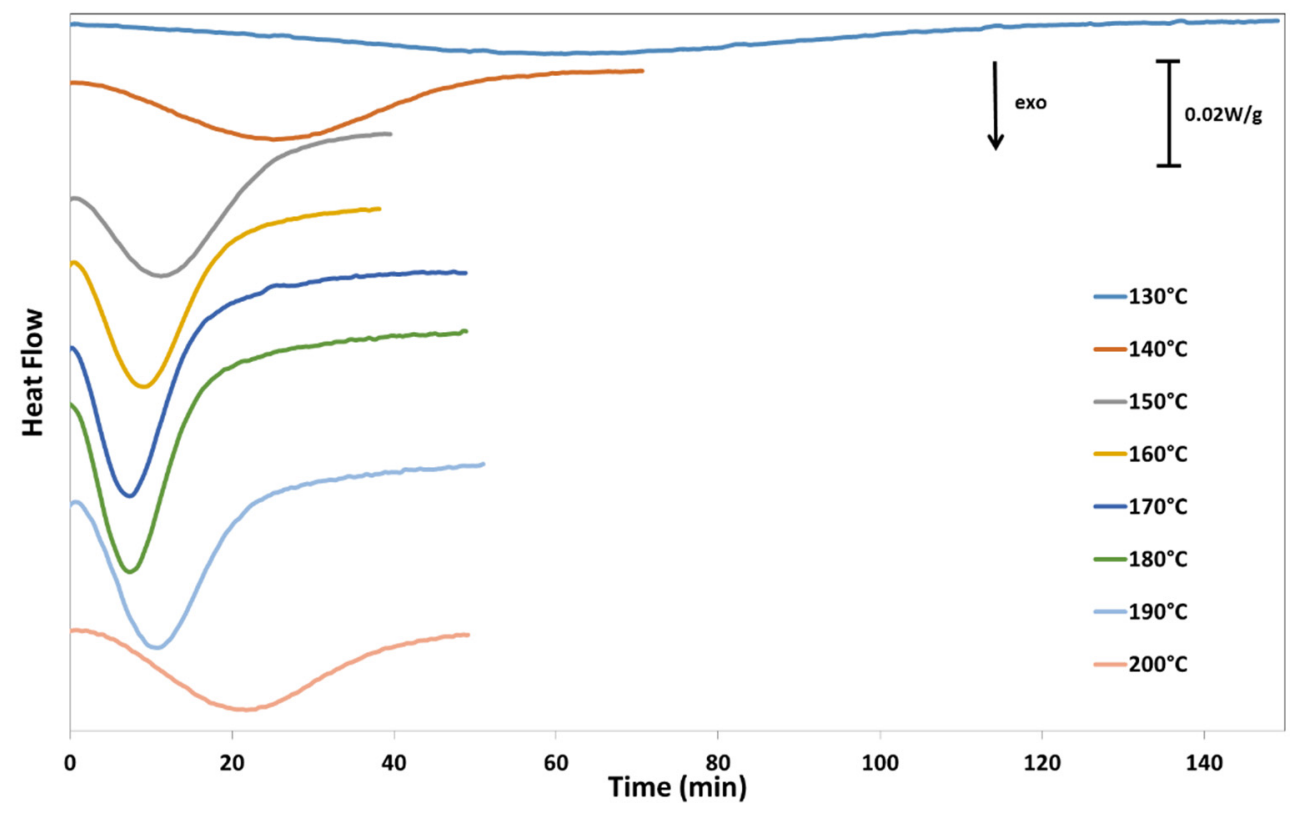

Figure 3. Differential scanning calorimetry (DSC) signal recorded during the isothermal crystallization of $\mathrm{PEI}_{4.9} \mathrm{~T}$ at different temperatures (from $130{ }^{\circ} \mathrm{C}$ to $200{ }^{\circ} \mathrm{C}$ ). The color code for temperatures is embedded in the figure. 


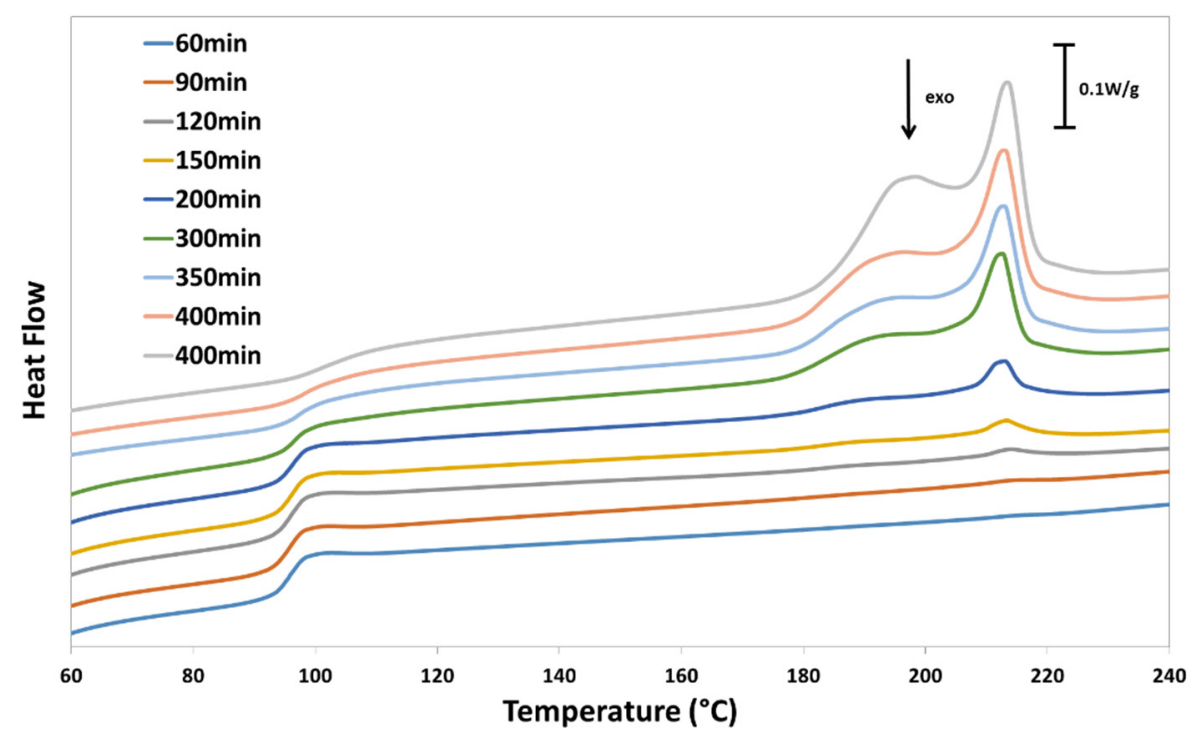

Figure 4. DSC signal recorded upon heating $\mathrm{PEI}_{17.1} \mathrm{~T}$ after different crystallization isotherms at $170{ }^{\circ} \mathrm{C}$. The duration of the isotherms is embedded in the figure.

Figure 3 presents DSC thermograms measured on amorphous $\mathrm{PEI}_{4.9} \mathrm{~T}$ during isothermal treatments at different temperatures. These isothermal treatments were obtained after the complete melting of the material. It clearly appears on this figure that all curves presented an exothermic event taking place over a varying period of time depending on the isothermal temperature. This event was attributed to the crystallization of the $\mathrm{PEI}_{4.9} \mathrm{~T}$. It is to be noted that, for isothermal temperatures from $150{ }^{\circ} \mathrm{C}$ to $190{ }^{\circ} \mathrm{C}$, the heat flow value recorded at the beginning of the thermogram was lower than that recorded at the end. This particular behavior could be attributed to the beginning of the crystallization process prior to the isothermal start. Actually, for those temperatures, the crystallization started during the cooling stage from the melt. The amount of material that crystallized before reaching the isothermal temperature could not be evaluated, but it was assumed to be small with respect to the whole thermograms. It is, thus, neglected in the rest of this paper.

From Figure 3, it was possible to determine the crystallization progress at any time for the studied temperatures.

Figure 4 presents DSC thermograms measured on $\mathrm{PEI}_{17.1} \mathrm{~T}$ after different isothermal treatments at $170{ }^{\circ} \mathrm{C}$. The duration of the isothermal period varies from 60 minutes to 600 minutes. It can be firstly observed on Figure 4 that a heat capacity (Cp) jump attributed to the glass transition of the material appeared at around $95^{\circ} \mathrm{C}$. The amplitude of this $\mathrm{Cp}$ jump decreased as isothermal period increased.

A second endothermic event appeared between $180^{\circ} \mathrm{C}$ and $210{ }^{\circ} \mathrm{C}$, with the size of this event increasing as the isothermal period increased. It is to be noted that this event was itself composed of two sub-events. This endotherm was attributed to the melting of the crystalline part of the material obtained during the isothermal treatment. The opposite and concomitant evolution of both the amplitude of the Cp jump and the enthalpy of the peak confirmed this hypothesis. The presence of several peaks in the melting endotherm revealed that the melting of crystalline PEIT took place in different steps. Such a behavior was already highlighted on many polymers like PET [14], and it was attributed to the presence of several crystal types formed by primary or secondary crystallization.

In the present study, the global melting endotherm was considered to evaluate the crystallinity of studied PEIT.

From Figures 3 and 4 , the evolution of the weight fraction crystallinity $\left(X_{t}\right)$ could be determined according to Equations (2) and (3), respectively. The $X_{t}$ evolution as a function of the isothermal crystallization time and temperature for $\mathrm{PEI}_{4.9} \mathrm{~T}$ and $\mathrm{PEI}_{17.1} \mathrm{~T}$ is presented in Figure $5 \mathrm{a}, \mathrm{b}$. In Figure $5 c, d$, the plot of $\log \left(-\ln \left(1-X_{t}\right)\right)$ as a function of $\log (t)$ is also given for the same experimental data. 


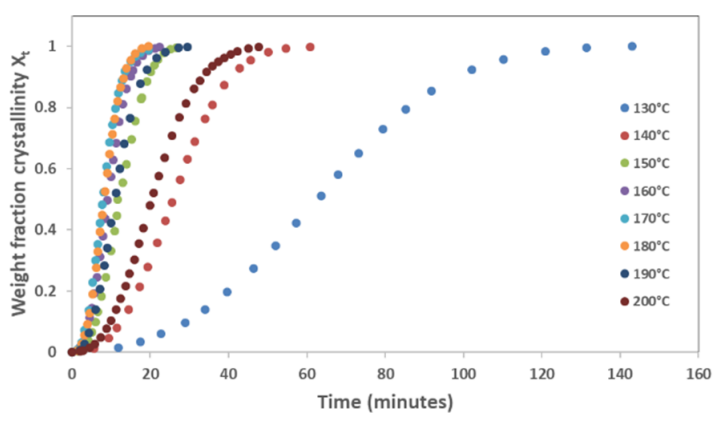

(a)

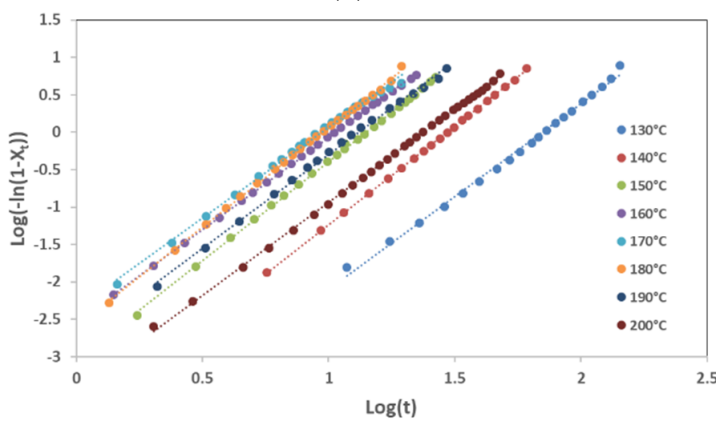

(c)

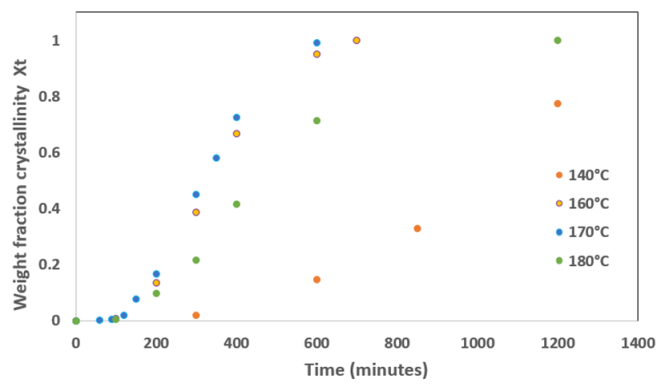

(b)

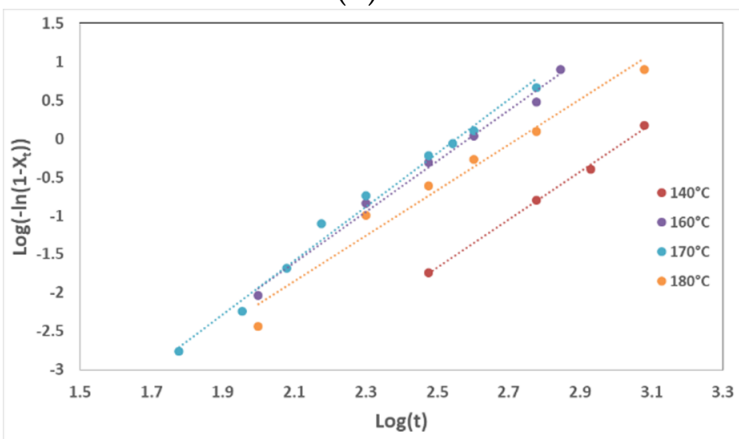

(d)

Figure 5. Weight fraction crystallinity $X_{t}$ versus isothermal crystallization time $t(\mathbf{a}, \mathbf{b})$ and $\log (-\ln (1-$ $\left.X_{t}\right)$ ) versus $\log (t)(\mathbf{c}, d)$ for several crystallization temperatures. The two PEIT samples presented here are $\mathrm{PEI}_{4.9} \mathrm{~T}(\mathbf{a}, \mathbf{c})$ and $\mathrm{PEI}_{17.1} \mathrm{~T}(\mathbf{b}, \mathbf{d})$.

From the plots in Figure $5 c, d$, the crystallization half time $t_{1 / 2}$, Avrami index $n$, and crystallization rate constant $\mathrm{K}$ were obtained using the following Avrami equation:

$$
X(t)=1-e^{-(K \times t)^{n}}
$$

where $X(t)$ is the relative crystallinity at time $t, K$ is the crystallization rate constant $\left(\min ^{-1}\right)$, and $n$ is the Avrami exponent linked to the geometry of crystals. This equation may also be expressed in the following form:

$$
\log [-\ln (1-\mathrm{X})]=\operatorname{nlog}(\mathrm{t})+\mathrm{nlog}(\mathrm{K}) .
$$

This second form of the Avrami equation gives easy access to parameters $\mathrm{n}$ and $\mathrm{K}$, as well as $t_{1 / 2}$, corresponding to the half crystallization time. Those three essential parameters to describe the crystallization kinetics of polymers are gathered in Table 2.

Table 2 gathers the Avrami parameters measured on PET and PEIT with varying isosorbide contents. Those parameters were obtained by fitting experimental crystallization kinetics with the Avrami equation (Equation (7)). Examples of such a fit are presented in Figure 5c,d.

It firstly appears from Table 1 that the isosorbide content slowed down the crystallization kinetics of PEIT. The $\mathrm{t}_{1 / 2}$ was actually multiplied by 100 between $\mathrm{PEI}_{4.9} \mathrm{~T}$ and $\mathrm{PEI}_{20.8} \mathrm{~T}\left(\mathrm{t}_{1 / 2}=8 \mathrm{~min}\right.$ and $\mathrm{t}_{1 / 2}=813 \mathrm{~min}$, respectively at $170{ }^{\circ} \mathrm{C}$ ).

In parallel, it is to be noted that the isosorbide content did not clearly have an impact on the value of parameter $\mathrm{n}$. Actually, $\mathrm{n}$ always remained in the range 2-3. Higher values of parameter $\mathrm{n}$ were obtained for $\mathrm{PEI}_{20.8} \mathrm{~T}$ at $150{ }^{\circ} \mathrm{C}$ and $180^{\circ} \mathrm{C}$ (3.73 and 3.41, respectively). However, for those particular cases, crystallization kinetics were so long that a limited number of points were taken into account for Avrami equation fitting. This limited number of points was most probably at the origin of a less accurate fitting, leading to higher values of parameter $n$. More generally, $\mathrm{n}$ values shown in Table 2 tended to show that the geometry of PET crystals was not modified by the introduction of isosorbide molecules in the structure of the polymer (for the isosorbide content range between 0 and $20 \mathrm{~mol} . \%$ ). 
Table 2. Avrami parameters obtained on PET and PEIT with different isosorbide contents for varying isothermal crystallization temperatures. Crystallization was performed on previously melted materials.

\begin{tabular}{|c|c|c|c|c|}
\hline Samples Code & $\mathrm{T}\left({ }^{\circ} \mathrm{C}\right)$ & $K\left(\min ^{-1}\right)$ & $\mathbf{n}$ & $t_{1 / 2}(\min )$ \\
\hline \multirow[t]{8}{*}{ PET } & 110 & 0.03 & 2.08 & 27.7 \\
\hline & 115 & 0.07 & 2.07 & 10.8 \\
\hline & 120 & 0.15 & 2.12 & 5.7 \\
\hline & 130 & 0.47 & 2.01 & 1.8 \\
\hline & 140 & 1.11 & 1.93 & 0.7 \\
\hline & 217 & 0.24 & 2.43 & 3.6 \\
\hline & 220 & 0.19 & 2.74 & 4.7 \\
\hline & 224 & 0.12 & 2.62 & 7.5 \\
\hline \multirow{6}{*}{$\mathrm{PEI}_{4.9} \mathrm{~T}$} & 150 & 0.071 & 2.65 & 12.2 \\
\hline & 160 & 0.09 & 2.46 & 9.2 \\
\hline & 170 & 0.11 & 2.43 & 8.1 \\
\hline & 180 & 0.11 & 2.66 & 8.3 \\
\hline & 190 & 0.076 & 2.51 & 11.3 \\
\hline & 200 & 0.043 & 2.5 & 20.2 \\
\hline \multirow[t]{5}{*}{$\mathrm{PEI}_{6.5} \mathrm{~T}$} & 150 & 0.041 & 2.76 & 21.4 \\
\hline & 160 & 0.062 & 2.58 & 13.9 \\
\hline & 170 & 0.07 & 2.52 & 12.3 \\
\hline & 180 & 0.063 & 2.62 & 13.9 \\
\hline & 190 & 0.039 & 2.61 & 22.1 \\
\hline \multirow[t]{5}{*}{$\mathrm{PEI}_{9.8} \mathrm{~T}$} & 140 & 0.0103 & 2.86 & 85.1 \\
\hline & 150 & 0.019 & 2.51 & 44.3 \\
\hline & 160 & 0.029 & 2.63 & 31.1 \\
\hline & 170 & 0.025 & 2.44 & 34.4 \\
\hline & 180 & 0.018 & 2.87 & 49.1 \\
\hline \multirow[t]{4}{*}{$\mathrm{PEI}_{10.9} \mathrm{~T}$} & 150 & 0.0081 & 2.72 & 107.8 \\
\hline & 160 & 0.012 & 2.26 & 69.6 \\
\hline & 170 & 0.013 & 2.66 & 67.3 \\
\hline & 180 & 0.01 & 2.26 & 82.1 \\
\hline \multirow[t]{5}{*}{$\mathrm{PEI}_{17.1} \mathrm{~T}$} & 140 & 0.00091 & 3.11 & 976.5 \\
\hline & 160 & 0.0025 & 2.76 & 348.7 \\
\hline & 170 & 0.0028 & 2.91 & 318.9 \\
\hline & 180 & 0.0019 & 2.31 & 455.5 \\
\hline & 190 & 0.00067 & 2.03 & 1247.5 \\
\hline \multirow[t]{4}{*}{$\mathrm{PEI}_{20.8} \mathrm{~T}$} & 150 & 0.00081 & 3.73 & 1122 \\
\hline & 160 & 0.00116 & 3.03 & 765 \\
\hline & 170 & 0.00109 & 2.99 & 813 \\
\hline & 180 & 0.00082 & 3.41 & 1094 \\
\hline
\end{tabular}

Figure 6 presents the evolution of $t_{1 / 2}$ values given in Table 2 as a function of temperature for isothermal crystallization of PEIT with varying isosorbide contents.

Results presented in Figure 6 give a good overview of the impact of the isosorbide content on the crystallization kinetics of PEIT. It also clearly appears from Figure 6 that the crystallization kinetics of PET and PEIT presented a maximum speed at around $170^{\circ} \mathrm{C}$. This temperature remained the same over the isosorbide range studied. This variation of the half crystallization time is well known for polymers. It is actually the result of the competition between the thermodynamic driving force and the mobility of the molecules. When decreasing the temperature from the melt, the first increases while the second decreases. On the one hand, between the melting temperature and the maximum crystallization speed temperature, the thermodynamic effect was predominant which was caused by an increase in crystallization speed. On the other hand, below $170^{\circ} \mathrm{C}$, the molecular mobility became so low that the overall crystallization speed was affected and decreased. 


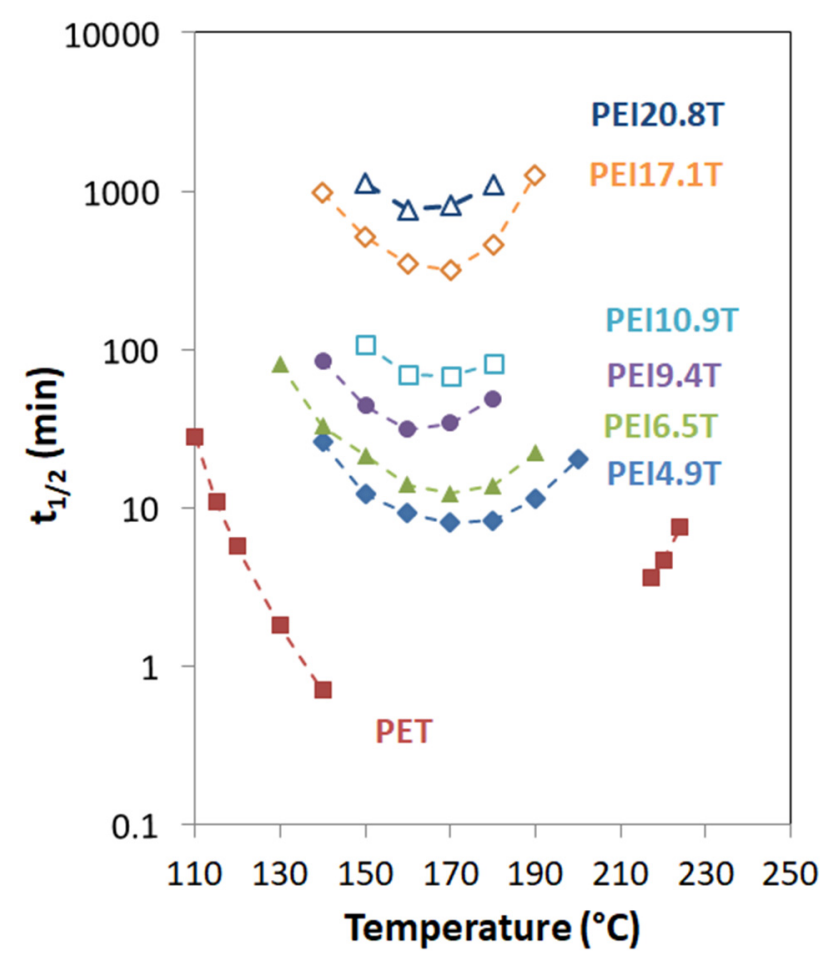

Figure 6. Evolution of $t_{1 / 2}$ with temperature for isothermal crystallization of PEIT with varying isosorbide contents.

Figure 7 presents the impact of the isosorbide molar content on the crystallization half time at the maximum crystallization speed temperature $\left(170^{\circ} \mathrm{C}\right)$. This graph highlights that the increase in the molar content of isosorbide induced an exponential increase of $t_{1 / 2}$. The embedded equation with a regression coefficient $R^{2}$ almost equal to 1 confirmed this effect of isosorbide.

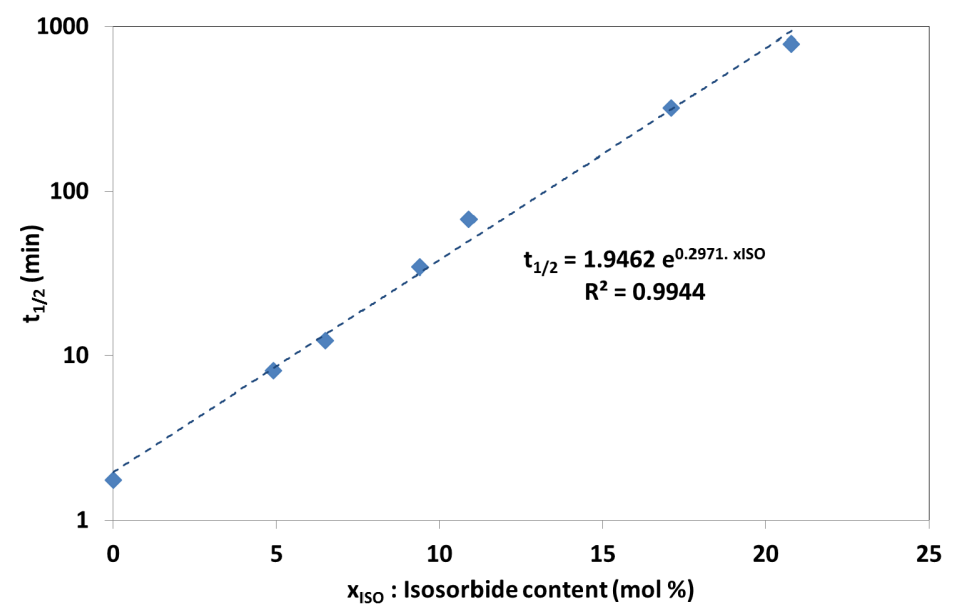

Figure 7. Evolution of the half crystallization time as a function of the isosorbide molar content of PEIT for isothermal temperature of $170^{\circ} \mathrm{C}$.

Figure 8 shows the effect of the isosorbide content on the melting behavior of PEIT (melting temperature and melting enthalpy). It actually appears from Figure 8 that the increase in isosorbide content led to a decrease in both melting temperature and melting enthalpy. In the isosorbide content range studied $\left(0 \%\right.$ to $20 \%$ ), the melting temperature decreased by more than $40^{\circ} \mathrm{C}$ (from $249{ }^{\circ} \mathrm{C}$ to $207^{\circ} \mathrm{C}$ ). In the meantime, the maximum melting enthalpy was reduced by around $50 \%$ (from 54.7 to $28.4 \mathrm{~J} / \mathrm{g})$. 


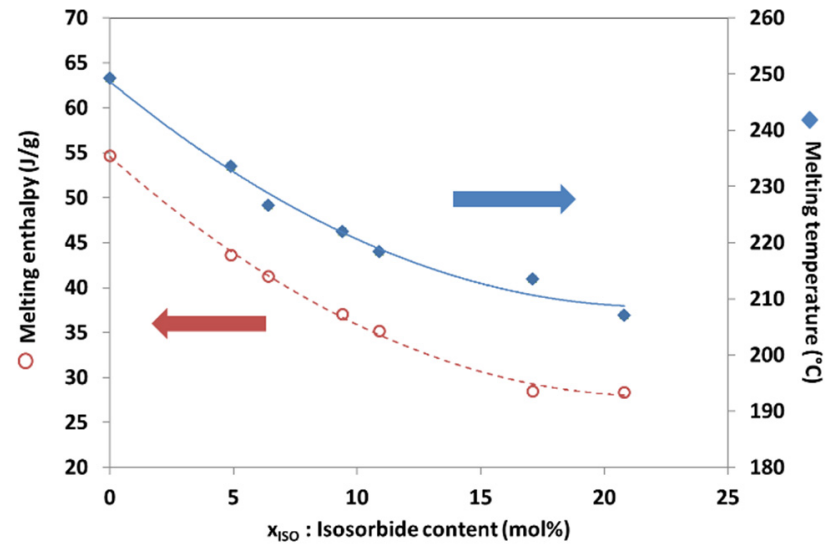

Figure 8. Evolution of the melting temperature and melting enthalpy as a function of the molar content of isosorbide. Melting enthalpy was measured after complete crystallization at $170{ }^{\circ} \mathrm{C}$.

The decrease in maximum melting enthalpy described the reducing capability of the material to crystallize when adding isosorbide. As seen in Table 1, replacing ethylene glycol by isosorbide induced a decrease in both the ET sequence length in the polymer and the percentage of those sequences. At the same time, the molar fraction of ITI sequences increased but with an almost constant average sequence length (between 1 and 1.4). As mentioned by Aoki et al. [15], the minimum sequence length for possible crystallization is about five. This means that ITI sequences are too small to crystallize. Therefore, the crystallinity of PEIT should only come from the ETE sequences. To validate this hypothesis, X-ray diffraction analyses were carried out on all crystallized samples prepared in this study. Pure PET and pure PIT were used as reference samples.

Firstly, contrary to what is commonly admitted in the literature [1,16], PIT was found to be subjected to crystallization when precipitated in cold methanol from a polymer solution in chloroform. As shown in Figure 9, this polymer displayed a multiple melting peak with a first endotherm around $194{ }^{\circ} \mathrm{C}(10.4 \mathrm{~J} / \mathrm{g})$ and a second at $241^{\circ} \mathrm{C}(5.5 \mathrm{~J} / \mathrm{g})$. The annealing of that polymer at $200^{\circ} \mathrm{C}$ for $7 \mathrm{~h}$ induced changes in the melting profile which led to modifications of the crystals. Two melting peaks at $206^{\circ} \mathrm{C}$ $(9.4 \mathrm{~J} / \mathrm{g})$ and $234^{\circ} \mathrm{C}(4.2 \mathrm{~J} / \mathrm{g})$ were recorded. As anticipated, these endotherms disappeared on the second heating scan due to the low ability of the polymer to organize for crystallization. This sample was, thus, not considered in this thermal crystallization study.

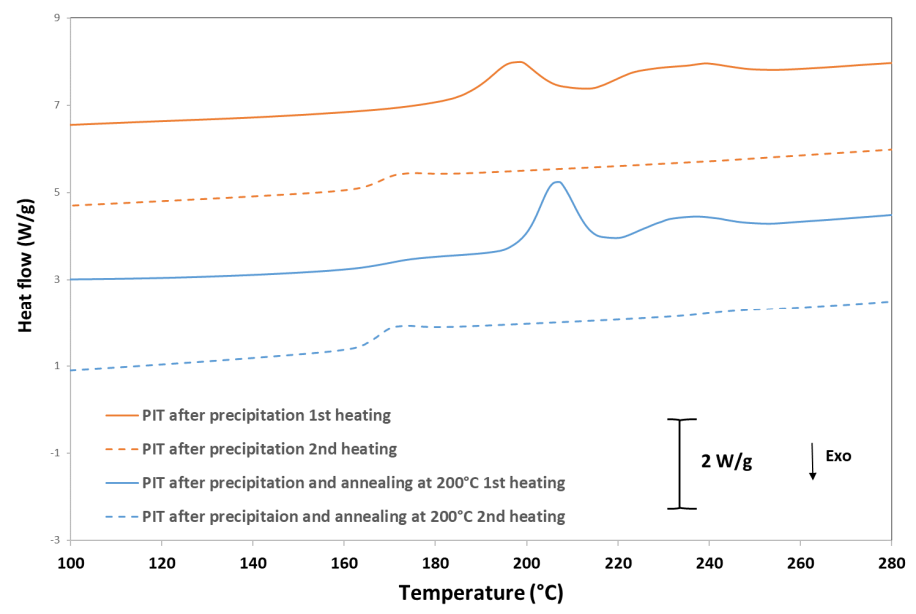

Figure 9. DSC thermograms of PIT crystallized from solution and after annealing treatment of $7 \mathrm{~h}$ at $200{ }^{\circ} \mathrm{C}$. 
Figure 10 presents X-ray diffractograms obtained on semi-crystalline PET, $\mathrm{PEI}_{5} \mathrm{~T}, \mathrm{PEI}_{9.5} \mathrm{~T}$, and $\mathrm{PEI}_{19.5} \mathrm{~T}$ crystallized from melt, as well as that of PIT measured on a polymer crystallized from solution.

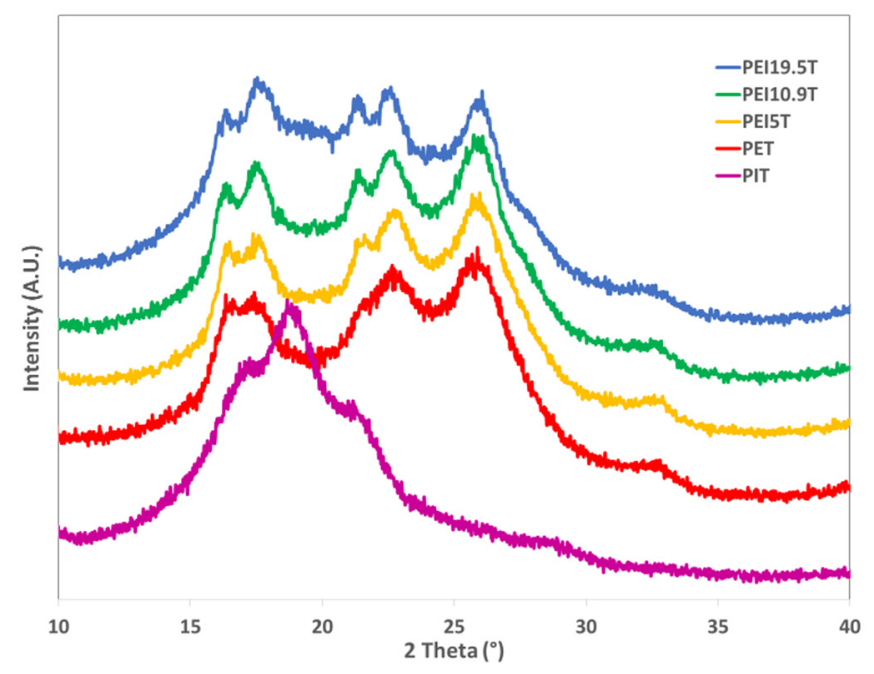

Figure 10. X-ray diffractograms of semi-crystalline PET, PIT, and PEIT. The isosorbide content of PEIT samples is embedded in the figure.

For PEIT, the peak intensity decreased with increasing isosorbide levels. This confirmed the decrease in the degree of crystallinity measured by the melting enthalpy in DSC. The diffraction spectra observed for PEITs were close to those of PET. As suggested by Zhang [17], this indicates that the crystalline parts of the PEITs are related to PET patterns. However, we cannot rule out the fact that the presence of isosorbide units can disrupt the crystallization of the PET units, with this disturbance reflected by the observed peak offsets as a function of the isosorbide level. Finally, the spectrum recorded on pure crystalline PIT had diffraction peaks very different from those of PET and PEIT. This led to confirming the previous hypothesis according to which, for the isosorbide contents studied here (up to $20 \%$ ), the PIT patterns present in the PEIT samples were not crystallized.

\section{Conclusions}

In this study, the crystallization of poly(ethylene-co-isosorbide terephthalate) copolyesters was assessed. For that, PEIT samples with various amounts of isosorbide going from 4.8 to $20.8 \mathrm{~mol}$ \% were successfully synthetized with a random distribution of isosorbide moieties in the polymer backbone as revealed by ${ }^{13} \mathrm{C}-\mathrm{NMR}$.

First results showed clearly that the presence of isosorbide modified the crystallization behavior of PET. Actually, increasing the isosorbide content led to an exponential increase in the crystallization half time $\left(\mathrm{t}_{1 / 2}=1.946 \cdot \exp \left(0.297 . \mathrm{x}_{\mathrm{ISO}}\right)\right.$ at $\left.170^{\circ} \mathrm{C}\right)$. This increase in crystallization time went together with the decrease in melting temperature (from $250{ }^{\circ} \mathrm{C}$ for PET to $207^{\circ} \mathrm{C}$ for $\mathrm{PEI}_{20} \mathrm{~T}$ ) and the decrease in overall crystallinity (from $55 \mathrm{~J} / \mathrm{g}$ to $28 \mathrm{~J} / \mathrm{g}$ melting enthalpy for PET and for $\mathrm{PEI}_{20} \mathrm{~T}$ crystallized at the maximum, respectively).

In addition, comparative X-Ray diffraction analysis of crystallized PET, PEIT, and PIT samples clearly indicated that ethylene terephthalate moieties were the only ones to crystallize.

Finally, mathematical fit of the Avrami model was done on experimental data of crystallization kinetics for PET and PEIT. In all cases, the value of the Avrami's exponent (n) was close to 3, indicating a three-dimensional (3D) spherulitic growth of the crystals.

All parameters studied here are essential knowledge for further processing of poly(ethylene-co-isosorbide terephthalate) copolyesters. They show that, with isosorbide contents higher than $15 \mathrm{~mol} \%$, these copolyesters are difficult and long to crystallize. Potential applications are, 
thus, different depending on the isosorbide content. Polymers that are able to "quickly" crystallize could be used for injection stretch blow molding of hot filling bottle or for making fibers, whereas amorphous ones would be more perfectly suitable for making high-transparency polymers for optical application or as a substitute of polycarbonate in food contact applications. In addition these isothermal kinetics give some important parameters for the solid-state post-condensation of these copolyesters, i.e., optimized crystallization temperature and time, and maximal temperature to be used for the solid state.

Author Contributions: Investigation, F.F.; writing—original draft, N.D. and N.J.; writing—review and editing, P.H. and R.S.-L. All authors have read and agreed to the published version of the manuscript

Funding: This research received no external funding.

Conflicts of Interest: The authors declare no conflict of interest.

\section{References}

1. Fenouillot, F.; Rousseau, A.; Colomines, G.; Saint-Loup, R.; Pascault, J.P. Polymers from renewable 1, 4: 3, 6-dianhydrohexitols (isosorbide, isomannide and isoidide): A review. Prog. Polym. Sci. 2010, 35, 578-622. [CrossRef]

2. Kricheldorf, H.R. Sugar Diols as Building Blocks of Polycondensates. J. Macromol. Sci. Part C Polym. Rev. 1997, 37, 599-631. [CrossRef]

3. Blache, H.; Mechin, F.; Rousseau, A.; Fleury, E.; Pascault, J.P.; Alcouffe, P.; Jacquel, N.; Saint-Loup, R. New bio-based thermoplastic polyurethane elastomers from isosorbide and rapeseed oil derivatives. Ind. Crops Prod. 2018, 121, 303-312. [CrossRef]

4. Bersot, J.C.; Jacquel, N.; Saint-Loup, R.; Fuertes, P.; Rousseau, A.; Pascault, J.P.; Spitz, R.; Fenouillot, F.; Monteil, V. Efficiency Increase of Poly (ethylene terephthalate-co-isosorbide terephthalate) Synthesis using Bimetallic Catalytic Systems. Macromol. Chem. Phys. 2011, 212, 2114-2120. [CrossRef]

5. Adelman, D.J.; Charbonneau, L.F.; Ung, S. Process for Making Poly(ethylene-co-isosorbide) Terephthalate Polymer. U.S. Patent 20030232959, 14 June 2002.

6. Stanley, N.; Chenal, T.; Delaunay, T.; Saint-Loup, R.; Jacquel, N.; Zinck, P. Bimetallic catalytic systems based on $\mathrm{Sb}$, Ge and Ti for the synthesis of poly(ethylene terephthalate-co-isosorbide terephthalate). Polymers 2017, 9, 590. [CrossRef] [PubMed]

7. Adelman, D.J.; Greene, R.N.; Putzig, D.E. Poly (1, 3-propylene-co-1, 4: 3, 6-dianhydro-D-sorbitol terephthalate) and Manufacturing Process. U.S. Patent 20030232960, 14 June 2002.

8. Kricheldorf, H.R.; Behnken, G.; Sell, M. Influence of Isosorbide on Glass-Transition Temperature and Crystallinity of Poly (butylene terephthalate). J. Macromol. Sci. Part A Pure Appl. Chem. 2007, 44, 679-684. [CrossRef]

9. Sablong, R.; Duchateau, R.; Koning, C.E.; Wit, G.; Es, D.; Koelewijn, R.; Haveren, J. Incorporation of isosorbide into poly (butylene terephthalate) via solid-state polymerization. Biomacromolecules 2008, 9, 3090-3097. [CrossRef] [PubMed]

10. Legrand, S.; Jacquel, N.; Amedro, H.; Saint-Loup, R.; Pascault, J.P.; Rousseau, A.; Fenouillot, F. Synthesis and properties of poly(1,4-cyclohexanedimethylene-co-isosorbide terephthalate), a biobased copolyester with high performances. Eur. Polym. J. 2019, 115, 22-29. [CrossRef]

11. Storbeck, R.; Ballauff, M. Synthesis and thermal analysis of copolyesters deriving from 1, 4: 3, 6-dianhydrosorbitol, ethylene glycol, and terephthalic acid. J. Appl. Polym. Sci. 1996, 59, 1199-1202. [CrossRef]

12. Göltner, W. Relationship between Polyester Quality and Processability: Hands-On Experience. In Modern Polyesters: Chemistry and Technology of Polyesters and Copolymers; John Wiley \& Sons Inc.: New York, NY, USA, 2004; pp. 435-493. ISBN 9780470090688.

13. Jacquel, N.; Saint-Loup, R.; Pascault, J.P.; Rousseau, A.; Fenouillot, F. Bio-based alternatives in the synthesis of aliphatic-aromatic polyesters dedicated to biodegradable film applications. Polymer 2015, 59, 234-242. [CrossRef]

14. Lu, X.F.; Hay, J.N. Isothermal crystallization kinetics and melting behaviour of poly(ethylene terephthalate). Polymer 2001, 42, 9423-9431. [CrossRef] 
15. Aoki, Y.; Li, L.; Amari, T.; Nishimura, K.; Arashiro, Y. Dynamic Mechanical Properties of Poly(ethylene terephthalate)/Poly(ethylene 2,6-naphthalate) Blends. Macromolecules 1999, 32, 1923-1929. [CrossRef]

16. Storbeck, R.; Rehahn, M.; Ballauff, M. Synthesis and properties of high-molecular-weight polyesters based on 1, 4: 3, 6-dianhydrohexitols and terephthalic acid. Die Makromol. Chem. 1993, 194, 53-64. [CrossRef]

17. Zhang, F.; Wang, Q.; Wang, L.; Bai, Y. Implementing plant-derived isosorbide and isomannide as comonomers for polyester synthesis: Effects of crystallization properties on optical properties. J. Appl. Polym. Sci. 2017, 134, 45444. [CrossRef]

(C) 2020 by the authors. Licensee MDPI, Basel, Switzerland. This article is an open access article distributed under the terms and conditions of the Creative Commons Attribution (CC BY) license (http://creativecommons.org/licenses/by/4.0/). 